\title{
Pengelolaan Institutional Repository Universitas Islam Negeri Sunan Kalijaga Berdasarkan Model Open Archival Information System
}

\author{
Muh Ahlis Ahwan ${ }^{1 *}$ \\ ${ }^{1}$ Universitas Islam Negeri Walisongo \\ *Korespondensi: ahlisahwan@ walisongo.ac.id
}

\begin{abstract}
This study aims to explore Institutional Repository management at UIN Sunan Kalijaga by using the Open Archival Information System (OAIS) model. OAIS model is an archiving model designed by Consultative Committee for Space Data System (CCSDS) that is recognized by International Standards Organization (ISO) as 14.721 international standards, which can be recommended to be referred for digital libraries that emphasize on preservation functions such as the UIN Sunan Kaljaga Digital Library. This research employes qualitative method and the data was collected using observation and interviews. The data analysis consist of data reduction, data presentation, verification and writing a conclusion.. The data validity test was conducted by triangulation technique. The results show that the UIN SUnan Kalijaga Yogayakarta Institutional Repository has well met the OAIS model components. It fullfils the system environment internal and external to the packaging of information and objects. However, several entities need to be addressed; collection variations, members monitoring, developing the packaging designs and migration plans, as well as submission agreement. Although a few entities need to be fulfilled, the Institutional Repository of UIN Sunan Kalijaga already manages most of OAIS aspects quite well. The results of this study benfit institutional repositories in developing digital library governance emphasizing data preservation.
\end{abstract}

Keywords: institutional repositories; oais model; open archival information system; digital library; institutional repository management; data preservation

\begin{abstract}
Abstrak
Penelitian ini bertujuan untuk menganalisis tata kelola Institutional Repository UIN Sunan Kalijaga dengan menggunakan model Open Archival Information System (OAIS), sebuah model pengarsipan dari Consultative Committee for Space Data System (CCSDS) yang telah diakui International Standart Organization (ISO) sebagai standar internasional 14.721 yang dapat digunakan untuk perpustakaan digital yang menekankan pada fungsi preservasi. Penelitian ini menggunakan pendekatan kualitatif dengan teknik pengumpulan data melalui observasi, wawancara, dan meninjau beberapa document terkait. Data yang terkumpul kemudian dianalisis melalui proses reduksi data, penyajian data, verifikasi serta penarikan kesimpulan. Uji keabsahan data dilakukan dengan triangulasi dan member check. Hasil analisis menunjukan pengelolaan Institutional Repository UIN Sunan Kalijaga Yogyakarta memenuhi komponen model OAIS; mulai dari lingkungan luar sistem, lingkungan dalam sistem, hingga kemasan informasi dan objek. Beberapa unsur masih perlu dilengkapi, misalnya variasi koleksi, pemantauan terhadap anggota, pengembangan desain kemasan, rencana migrasi, serta negosiasi kesepakatan/perjanjian penyerahan materi. Serta beberapa unsur lain yang perlu dilengkapi agar model OAIS dapat menjadi standar yang ideal bagi tata kelola Institutional Repository UIN Sunan Kalijaga Yogyakarta, dan dapat menjadi acuan bagi institutional repository lain yang ingin mengembangkan tata kelola perpustakaan digital yang menekankan preservasi data.
\end{abstract}

Kata kunci: repositori institusi; model oais; perpustakaan digital; manajemen repositori institusi; pelestarian data; preservasi data.

\section{PENDAHULUAN}

Sebuah catatan dari Pendit (2015) menyebutkan bahwa nyaris semua orang yang memiliki akses ke internet pernah melihat video klip pendek pidato Soeharto di YouTube ketika mengundurkan diri dari jabatannya sebagai Presiden, namun di mana video aslinya yang utuh? siapa yang menyimpannya, dan siapa yang boleh menontonnya? di mana pula naskah asli yang Soeharto pegang ketika membacakan pengunduran dirinya? pertanyaan tersebut bagi Pendit sendiri belum 
mendapatkan jawaban pasti, bahkan justru khawatir video asli tersebut sudah diperbanyak dan disimpan oleh pihak yang tidak jelas tanggungjawabannya. Memang kehadiran informasi sekarang yang "overload" telah membawa kerumitan tersendiri akan keaslian informasi yang disediakan, perlu kejelian menyeleksi, memilih, menghimpun, menyimpan, dan melestarikan informasi terutama bagi lembaga seperti arsip, museum, dokumentasi, ataupun perpustakaan.

Aktifitas perpustakaan termasuk menyeleksi informasi misalnya memastikan keaslian sebuah koleksi, karena suatu saat catatan dan jejak koleksi tersebut mungkin akan dibutuhkan dan ditelusur oleh pemustaka. Keaslian koleksi hendaknya memang tetap dilestarikan oleh perpustakaan dengan menyimpan koleksi secara fisik maupun melibatkan teknologi digital seperti repository, karena repository mulai dipercaya dapat menghemat ruangan dan membantu pencipta karya ketika menginginkan karya aslinya kembali (Reitz, 2004). Repository merupakan tempat untuk mengarsip local content dan grey literature suatu lembaga yang awalnya digunakan untuk kalangan lembaga itu sendiri. Namun maraknya simpanan informasi di internet dan permintaan pengguna untuk mengakses local content atau grey literature, lembaga akhirnya mulai membuka simpanannya kepada masyarakat luas (open access) dan juga sebagai wujud mempertahankan informasi (Arianto \& Subhan, 2012).

Simpanan local content atau grey literature suatu lembaga disimpan dalam institutional repository atau simpanan kelembagaan. Institutional repository merupakan simpanan karya yang dapat dihasilkan oleh lembaga sendiri atau lembaga lain yang dapat diselenggarakan oleh satu lembaga atau gabungan dari berbagai lembaga (Yeates, 2003), artinya beberapa lembaga dapat menyelenggarakan satu buah repository, atau justru satu lembaga dapat memiliki beberapa repository. Salah satu lembaga yang memiliki institutional repository adalah Perpustakaan Universitas Islam Negeri (UIN) Sunan Kalijaga Yogyakarta dengan simpanan kelembagaannya yaitu Institutional Repository UIN Sunan Kalijaga (http://digilib.uin-suka.ac.id).

Institutional Repository UIN Sunan Kalijaga awalnya mengoleksi file-file digital sejak tahun 2007 yang dihimpun dalam UINSIANA yang dikelola menggunakan GDL (Ganesha Digital Library) 4.2, tetapi setelah GDL diketahui terdapat kekurangan, koleksi digital dalam GDL akhirnya dimigrasi ke Eprints versi 2 pada bulan Mei 2012 (Yanto, 2013) dan terus berkembang menjadi versi 3. Koleksi Institutional Repository UIN Sunan Kalijaga sendiri pada Desember 2015 telah mencapai 16.704 (Universitas Islam Negeri Sunan Kalijaga, 2015) dan pada Juli 2015 telah menduduki peringkat ke-lima pada Webomatrics of Repositories untuk wilayah Indonesia (Consejo Superior de Investigaciones Científicas (CSIC), 2004). Koleksi Institutional Repository UIN Sunan Kalijaga meliputi skripsi, tesis, disertasi, laporan penelitian, laporan PPL (Praktik Pengenalan Lapangan), KKP (Kuliah Kerja Praktik), dan KKL (Kuliah Kerja Lapangan). Selain koleksi tersebut, Institutional Repository UIN Sunan Kalijaga juga menyediakan artikel jurnal, prosiding, soal ujian, dan informasi tentang kampus dalam berbagai format seperti teks, foto, audio, dan video.

Institutional Repository UIN Sunan Kalijaga merupakan institutional repository yang berkomitmen mengarsip karya dalam bentuk digital, agar seluruh masyarakat khususnya civitas akademika UIN Sunan Kalijaga dapat menyimpan serta mengakses koleksi tersebut di manapun dan kapanpun mereka berada, sehingga harapannya dapat meningkatkan citra lembaga UIN Sunan Kalijaga (Yanto, 2013). Institutional Repository UIN Sunan Kalijaga juga memiliki kebijakan institusi, pengelolaan berdasarkan local content, upaya menggiatkan pelestarian, dan menggunakan konsep open access sebagai interoperability, adanya legitimasi/mandat, perencanaan dengan lembaga induk, mendapat pendanaan yang jelas, adanya program digitalisasi, interoperability, adanya evaluasi dan pengukuran, promosi, serta strategi preservasi digital (Yanto, 2013).

Perkembangan institutional repository dengan simpanan data dan manajemen data sebenarnya sudah menjadi fenomena dan menjadi kehawatiran dalam mencari model yang stabil untuk mengelola perpustakaan digital pada awal abad 20-an (Hitchcock et al., 2007). Namun setelah 
muncul beberapa model referensi yang dapat diacu oleh lembaga pengelola perpustakaan digital khususnya institutional repository (Hitchcock et al., 2007), kehawatiran tersebut mulai sirna. Model tersebut antara lain model Rowlands dan Bawden, model Delos, dan model OAIS (Open Archival Information System) (Pendit, 2009).

Ketiga model di atas memiliki ciri dan segi teknis yang berbeda. Model Rowlands dan Bawdan terlalu umum untuk diterapkan pada perpustakaan digital, sementara model Delos kurang menekankan pada proses kerja yang sesungguhnya terjadi di dalam sebuah perpustakaan digital, sedangkan model OAIS adalah model yang sangat baik menggambarkan proses kerja (Pendit, 2009). Model OAIS juga banyak diadopsi oleh lembaga khususnya perpustakaan karena menekankan preservasi sebagaimana kebanyakan institutional repository pada umumnya (Bradley et al., 2007). OAIS merupakan sebuah model dari konsep institutional repository yang berguna sebagai pengarsipan (archival) dan lebih menekankan kepada fungsi pelestarian atau preservasi, bahkan tidak hanya menyimpan, mengawetkan atau mempertahankan bentuk, melainkan bagaimana informasi di dalamnnya selalu tersedia untuk dimanfaatkan selama mungkin.

Consultative Committee for Space Data Systems atau disingkat CCSDS sebagai organisasi luar angkasa yang rutin mengadakan pertemuan untuk mencari formula dan memberi rekomendasi solusi manajemen sistem data menyebutkan, bahwa model OAIS memiliki tiga komponen utama yang saling berkaitan, yakni lingkungan luar (external), lingkungan dalam (internal), dan kemasan informasi dan objek (Consultative Committee for Space Data Systems, 2012). Cara kerja model OAIS sebagai model referensi perpustakaan digital khususnya institutional repository diilustrasikan dalam gambar 1.

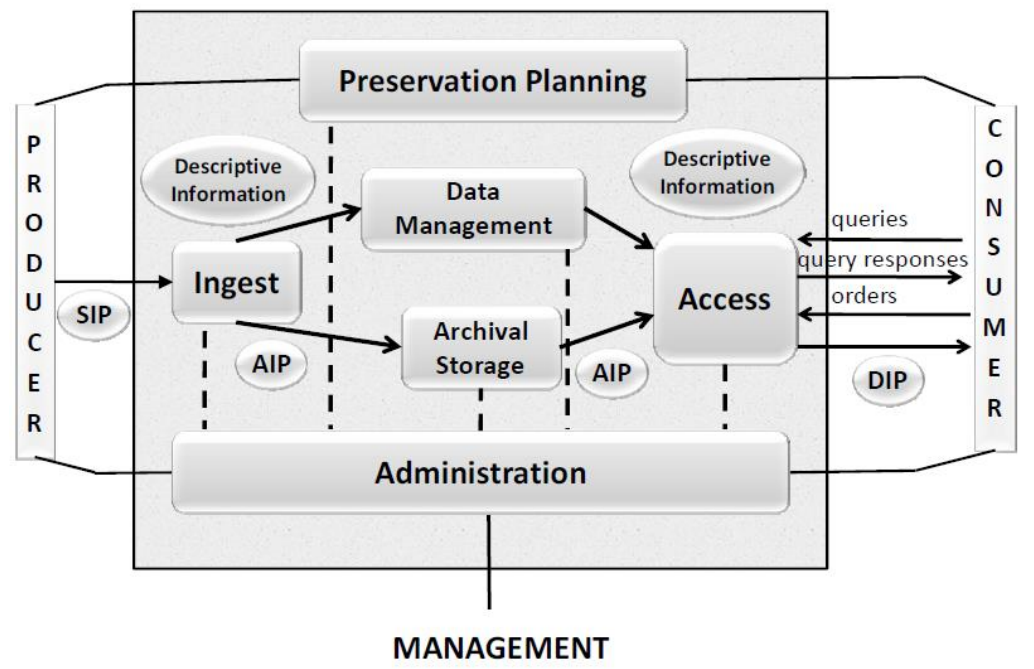

Gambar 1.

Fungsi Komponen OAIS

Sumber: (Consultative Committee for Space Data Systems, 2012)

OAIS memiliki 3 komponen utama yang saling berkesinambungan, pertama lingkungan external atau luar tempat sebuah OAIS berkegiatan yang terdiri dari 3 entitas, yakni producer, management, dan consumer. Kedua yaitu lingkungan internal atau dalam yang terdiri dari 6 entitas (ingest, archival storage, data management, preservation planning, access, administration) yang berfungsi sebagai perangkat, komponen-komponen fungsional, dan mekanisme kerja OAIS untuk menyelenggarakan kegiatan pelestarian. Ketiga adalah kemasan informasi dan objek yang menjadi konsentrasi dalam kegiatan pelestarian model OAIS, objek tersebut diproses dari producer ke dalam sistem OAIS, kemudian di dalam sistem OAIS, objek diproses antar komponen sistem OAIS, dan pada akhirnya dari sistem diproses menuju consumer. 
Proses tersebut nampak sebagai suatu kemasan informasi yang mengandung koleksi yang harus dilestarikan bersamaan dengan metadata yang telah diikat. Kemasan tersebut terbagi menjadi tiga komponen yakni submission information package (SIP), archival information package (AIP), dan dissemination information package (DIP) (Pendit, 2009).

Model OAIS diciptakan oleh CCSDS melalui berbagai upaya panjang dan berulang-ulang mulai dari penyusunan, ulasan, revisi, umpan balik pengguna saat diskusi lokakarya, sampai dengan tanggapan atas komentar. Model ini menggambarkan proses kerja dan akhirnya diakui International Standart Organization (ISO) sebagai Standar Internasional 14.721 pada tahun 2002 dan secara resmi diterbitkan pada tahun 2003 sebagai model referensi perpustakaan digital (Jones et al., 2006). Hal ini sejalan dengan Perpustakaan UIN Sunan Kalijaga yang telah berkomitmen untuk mengembangkan tata kelola institutional repository agar karya lembaganya dalam bentuk elektronik dapat dilestarikan dan dinikmati masyarakat luas selama mungkin (Yanto, 2013).

Model OAIS dapat menjadi model standar pengelolaan Institutional Repository UIN Sunan Kalijaga yang stabil, karena model OAIS dan Institutional Repository UIN Sunan Kalijaga memiliki ciri yang sama yakni mengupayakan pelestarian (Yanto, 2013). Selain itu model OAIS juga telah diakui sebagai standar ISO 14.721 yakni model referensi perpustakaan digital sejak tahun 2003 (Jones et al., 2006). Selanjutnya, model OAIS juga merupakan model yang sangat baik untuk menggambarkan proses kerja perpustakaan digital (Pendit, 2009); dan model OAIS ini adalah model yang paling banyak diadopsi oleh institutional repository (Bradley et al., 2007). Hal ini yang mendasari penelitian tentang tata kelola Institutional Repository UIN Sunan Kalijaga untuk melihat sejauhmana komponen dan entitas dalam model OAIS terpenuhi. Penulis memandang bahwa model OAIS dapat menjadi rekomendasi model yang stabil untuk tata kelola Institutional Repository UIN Sunan Kalijaga, dan dapat menjadi rujukan bagi lembaga lain yang mencari model untuk institutional repository yang menekankan kepada preservasi.

\section{METODE}

Penelitian ini menggunakan desain kualitatif dengan komponen dan entitas model OAIS sebagai alat untuk menganalisis tata kelola Institutional Repository UIN Sunan Kalijaga. Penelitian ini dilakukan sejak bulan Agustus 2015 hingga Agustus 2016. Subjek yang menjadi pusat data penelitian ini sebanyak tiga orang yang diberi tanggung jawab untuk mengelola Institutional Repository di Perpustakaan UIN Sunan Kalijaga Yogyakarta, yaitu Kepala Perpustakaan, Koordinasi Urusan (Kour) Preservasi dan Repository Digital, dan Kour Sistem Informasi dan Jaringan. Adapun objek penelitian yang penulis pilih adalah pengelolaan Institutional Repository UIN Sunan Kalijaga. Teknik pengambilan informan menggunakan purposive sampling dengan kriteria:

1. Pihak yang berperan besar dalam mengelola Institutional Repository UIN Sunan Kalijaga,

2. masih aktif mengelola Institutional Repository UIN Sunan Kalijaga,

Pengumpulan data dilakukan dengan melakukan observasi tidak langsung (observasi non partisipan), wawancara tak berstruktur, dan merujuk beberapa dokumen. Data di dalam penelitian ini diuji dengan validitas dan realibilitasnya dengan cara uji kredibilitas, yakni dengan cara triangulasi dan member check. Teknik analisis data yang digunakan adalah reduksi data, penyajian data, serta penarikan simpulan dan verifikasi. 


\section{HASIL DAN PEMBAHASAN}

\section{Ruang Lingkup External Institutional Repository UIN Sunan Kalijaga}

Lingkungan eksternal pada Institutional Repository UIN Sunan Kalijaga dapat diistilahkan sebagai pemangku kepentingan yang terlibat dalam menyelenggarakan seluruh kegiatan institutional repository. Lingkungan ini terdiri atas producer, consumer dan management.

\section{Producer}

Pihak yang berperan sebagai producer pada Institutional Repository UIN Sunan Kalijaga adalah sivitas akademika, universitas, perpustakaan, Eprints, PTIPD (Pusat Teknologi Informasi dan Pusat Data), dan pihak luar yang telah menciptakan koleksi bermuatan informasi UIN Sunan Kalijaga. Sejak berlakunya SK Rektor nomor 1.5 tahun 2016 tentang wajib simpan karya ilmiah, seluruh sivitas akademika baik itu dosen, karyawan, maupun mahasiswa wajib menyimpan hasil karya intelektualnya ke Institutional Repository UIN Sunan Kalijaga. Sesuai jawaban informan bahwa "yang menjadi penyetor materi di Digital Libary UIN Sunan Kalijaga adalah sivitas akademika UIN Sunan Kalijaga" (SH).

Dewan redaksi jurnal ilmiah sebagai sebuah organisasi di lingkungan UIN Sunan Kalijaga juga turut berkontribusi dalam mengunggah jurnal ilmiahnya di Institutional Repository UIN Sunan Kalijaga walaupun dewan redaksi juga mengupload artiklenya ke dalam portal khusus $e$ journal yang disediakan oleh UIN Sunan Kalijaga (http://ejournal.uin-suka.ac.id). Dewan redaksi ini terkadang menyerahkan jurnal ilmiahnya dalam bentuk softcopy ke petugas perpustakaan untuk diunggah di Institutional Repository UIN Sunan Kalijaga baik melalui email, datang langsung ke bagian perpustakaan, atau bahkan petugas yang mengambil terbitan ke dewan redaksi. Institutional Repository UIN Sunan Kalijaga juga menerima koleksi UINSIANA, yakni karya bermuatan UIN Sunan Kalijaga yang diterbitkan oleh pihak di luar lembaga, seperti artikel dalam surat kabar harian Kompas, Republika, Koran Sindo, Kedaulatan Rakyat, Bernas Jogja, Seputar Indonesia, Radar Jogja, dan lain-lain.

Ketika proses penyerahan koleksi dari producer ke aplikasi Eprints yang digunakan Institutional Repository UIN Sunan Kalijaga, pihak Perpustakaan UIN Sunan Kalijaga menyediakan perjanjian penyerahan (submission agreement) yang menjelaskan hak atas koleksi yang diserahterimakan, yakni hak cipta dan hak non eksklusif. Penulis memiliki hak atas cipta karya, sedangkan hak non eksklusif seperti menyimpan, memperbanyak, dan menyebarluaskan karya dipegang oleh UIN Sunan Kalijaga. Perjanjian penyerahan dilakukan producer saat proses upload mandiri pada http://pustaka.uin-suka.ac.id/, perjanjian dibuat dalam bentuk online, dan isi pernyataan perjanjian dibuat secara baku oleh Perpustakaan UIN Sunan Kalijaga, sehingga producer hanya dapat menyepakati perjanjian tersebut dengan cara checklist, tanpa ada pilihan yang ditawarkan. Penjanjian penyerahan ini hanya berlaku untuk mahasiswa saat menyerahkan tugas akhir saja, sedangkan bagi dosen, karyawan, dewan redaksi atau karya lain seperti UINSIANA masih dalam tahap perencanaan. Koleksi yang diserahkan kepada Institutional Repository UIN Sunan Kalijaga dikelola oleh Perpustakaan bekerjasama dengan PTIPD. Dari sisi teknis, perpustakaan mempercayakan Bagian Preservasi dan Repository Digital serta Bagian Sistem Informasi dan Jaringan untuk mengelola Institutional Repository UIN Sunan Kalijaga melalui aplikasi Eprints.

Setiap pihak penyedia koleksi Institutional Repository UIN Sunan Kalijaga mempunyai peran masing-masing dan saling berkesinambungan mendukung satu sama lain. Sivitas akademika dan pihak luar berperan sebagai pencipta koleksi, universitas sebagai penanggungjawab, perpustakaan berperan sebagai pemelihara, penyimpan, pelipatganda, dan penyebar koleksi, 
PTIPD berperan sebagai pangkalan data, dan Eprints berperan sebagai aplikasi untuk mengelola koleksi Institutional Repository UIN Sunan Kalijaga.

\section{Management}

Pihak yang berperan sebagai management pada Institutional Repository UIN Sunan Kalijaga adalah Rektor dan Kepala Perpustakaan UIN Sunan Kalijaga. Rektor sebagai penanggung jawab utama, dan Kepala Perpustakaan sebagai manajerial institutional repository. Kepala Perpustakaan membawahi seluruh pelaksana teknis, yakni Bagian Preservasi dan Repository Digital dan bagian Sistem Informasi dan Jaringan. Adapun semua usulan termasuk proposal anggaran untuk melaksanakan kegiatan pengelolaan Institutional Repository UIN Sunan Kalijaga diseleksi, dipilih, dihimpun, dan disetujui oleh Kepala Perpustakaan kemudian diajukan kepada Rektor dan Kementerian guna mendapatkan keputusan dana mengingat UIN Sunan Kalijaga adalah lembaga negara di bawah langsung Kementerian Agama. Sesuai pernyataan informan bahwa "Kalo dana pasti terpusat ya, perpustakaan yang mengupayakan itu lewat kepala perpustakaan, kemudian masuk ke dalam RKAKL dari sumber dana BLU dan BOPTN, serta APBN" (SRZ). Proposal anggaran kegiatan disusun setiap tahun dalam bentuk RKAKL (Rencana Kerja dan Anggaran Kementerian Lembaga/Negara) yang memuat semua rencana kegiatan ke depan, termasuk rencana pengelolaan Institutional Repository UIN Sunan Kalijaga yang belum terlaksana, contohnya adalah anggaran alihmedia (digitalisasi) tugas akhir.

Alih media dilaksanakan unit Preservasi dan Repository Digital UIN Sunan Kalijaga setiap tahun, alih media dilakukan terhadap koleksi tugas akhir mahasiswa dari awal hingga tahun 2007, dan lebih diprioritaskan untuk tugas akhir terbitan lama mulai tahun 1955 sampai dengan tahun 2000. Proses digitalisasi dilaksanakan dengan anggaran biaya besar dan membutuhkan waktu lama, sehingga proses digitalisasi perlu adanya teknologi yang mumpuni untuk mendukung pelaksanaannya.

Evaluasi Institutional Repository UIN Sunan Kalijaga dilakukan oleh perpustakaan dengan melihat jumlah koleksi yang sudah didigitalkan (Yanto, 2013). Evaluasi juga dilakukan setelah terbitnya pemeringkatan instittutional repository dari Webomatric of repositories yang secara tidak langsung juga telah dievaluasi oleh pihak luar (Priyanto, 2012). Pemeringkatan Webomatric dan jumlah koleksi yang disimpan menjadi tolak ukur kinerja tata Kelola Institutional Repository UIN Sunan Kalijaga agar Kepala perpustakaan sebagai penanggung jawab dapat membenahi dan meningkatkan kinerja Institutional Repository UIN Sunan Kalijaga bersama bawahannya.

\section{Consumer}

Consumer Institutional Repository UIN Sunan Kalijaga adalah seluruh pengguna di mana pun mereka berada baik secara individu, organisasi, maupun sistem. Pemanfaatan Institutional Repository UIN Sunan Kalijaga hanya memerlukan suatu perangkat dengan jaringan internet dan waktu aksesnya dapat kapan saja dan di mana saja kecuali untuk koleksi terbatas. Khusus koleksi terbatas hanya dapat diakses oleh sivitas akademika UIN Sunan Kalijaga yang sudah disetujui permohonan akses secara fulltext dan hanya diberikan waktu 24 jam setelah diberi akun. Sesuai petikan informan

"Yang jelas sivitas akademika di UIN terutama untuk mahasiswa, peneliti dan juga bagi dosen, karena dosen itu biar mengetahui judul apa saja yang sudah dibahas agar tidak terjadi duplikasi membahas tema, makannya dosen sini-sini itu ketika ingin memiliki akun atau hak akses itu tetep kita kasih"(SH).

Target pengguna Institutional Repository UIN Sunan Kalijaga adalah kalangan akademisi yang keahliannya disesuaikan dengan koleksi yang dilestarikan, seperti koleksi dalam bidang ilmu 
politik diperuntukkan kepada para politisi yang notabene memiliki keahlian dalam bidang tersebut, walaupun masyarakat umum juga bisa memanfaatkannya. Koleksi Institutional Repository UIN Sunan Kalijaga disediakan untuk mendukung karya-karya ilmiah yang akan diterbitkan, supaya penelitian atau research yang dilakukan kemudian tidak terindikasi memiliki kesamaan atau plagiat.

\section{Ruang Lingkup Internal Institutional Repository UIN Sunan Kalijaga}

\section{Ingest (pencerna)}

Koleksi yang dapat diterima oleh Institutional Repository UIN Sunan Kalijaga adalah karya apa pun yang dihasilkan oleh producer. Proses penerimaan (receive submission) koleksi diperoleh petugas melalui unggah mandiri, kiriman email, penyerahan kepada petugas secara langsung seperti dalam bentuk CD atau flash memory, bahkan hasil metode "jemput bola", yakni petugas yang mengambil langsung kepada producer. Unggah mandiri dilakukan oleh mahasiswa baik jenjang diploma (D3), sarjana (S1), magister (S2) maupun doktor (S3) pada laman www.pustaka.uinsuka.ac.id. Unggah Mandiri dilakukan mahasiswa dengan mengikuti panduan 'Prosedur Tetap Bebas Pustaka dan Unggah Tugas Akhir Mandiri Perpustakaan UIN Sunan Kalijaga Yogyakarta' (Hariyanto, 2016a). Tugas akhir yang diunggah berbentuk PDF (Portable Data Format) yang terdiri dari 3 (tiga) bagian, yaitu: (a) File tugas akhir BAB I dan BAB terakhir; (b) File tugas akhir mulai BAB II, III, atau IV (sebelum BAB terakhir); (c) File fulltext (mulai cover sampai terakhir).

Bagian pertama akan disediakan untuk diakses seluruh pengguna, bagian kedua akan diperuntukkan bagi pengguna yang menjadi anggota terkait plagiarism dan copy right (Yanto, 2013), dan bagian ketiga untuk mengontrol bagian pertama dan kedua, serta digunakan sebagai koleksi tugas akhir Institutional Repository UIN Sunan Kalijaga yang asli dan lengkap.

Petugas Perpustakaan UIN Sunan Kalijaga akan memeriksa kelengkapan setiap bagian tugas akhir setelah ketiga file sudah diunggah oleh mahasiswa. Pemeriksaan dilakukan untuk menjamin kualitas (quality assurance) koleksi dengan mengikuti pedoman 'Prosedur Tetap Verifikasi Soft Copy Tugas Akhir yang di Upload Mahasiswa'. Apabila tugas akhir yang diunggah belum valid, maka pertugas akan mengembalikan file kepada mahasiswa dengan catatan kekurangan yang harus diperbaiki. Namun apabila tugas akhir yang diunggah sudah valid, petugas Bagian Preservasi dan Repository Digital akan memindah file tersebut ke Institutional Repository UIN Sunan Kalijaga pada laman www.digilib.uin-suka.id dengan mengikuti 'Prosedur Upload File Karya Ilmiah (Wajib Simpan Karya Ilmiah) ke digilib.uin.suka.ac.id Perpustakaan UIN Sunan Kalijaga Yogyakarta' (Hariyanto, 2016b).

Karya mahasiswa selain tugas akhir, petugas menerima karya tersebut melalui email, unggah mandiri, diserahkan langsung ke petugas, atau dengan metode jemput bola. Setiap karya yang masuk ke sistem aplikasi Eprints Institutional Repository UIN Sunan Kalijaga, terlebih dahulu diulas (review) oleh petugas Bagian Preservasi dan Repository Digital untuk memastikan keadaan file koleksi tidak rusak atau hilang. Pemeriksaan koleksi selain tugas akhir dilakukan petugas tanpa suatu panduan tertulis karena belum dilakukan pengkajian terhadap keberagaman koleksi yang akan diulas (review), seperti jurnal ilmiah, buletin, prosiding, buku, pengumuman, dokumentasi, makalah, bahkan sampai pidato rektor. Petugas memeriksa keberagaman koleksi tersebut dengan inisiatif sendiri, seperti pengecekan halaman atau keberhasilan petugas dalam membuka file koleksi. Apabila koleksi tidak lolos review, maka petugas akan meminta pemilik atau penyetor karya untuk memperbaiki koleksi, sedangkan apabila koleksi valid, maka koleksi kemudian disetujui untuk disimpan ke dalam sistem Eprints.

Sembari sivitas akademika atau petugas mengunggah file koleksi ke sistem Institutional Repository UIN Sunan Kalijaga, sivitas akademika atau petugas juga membuat deskripsi informasi 
pada setiap karya yang disimpan (generate descriptive information) agar dapat mewakili dan diindeks oleh mesin pencari (seperti Google atau Yahoo) untuk ditemukan kembali. Petugas atau sivitas akademika membuat informasi deskripsi koleksi melalui aplikasi Eprints dengan standar metadata Dublin Core, yakni metadata yang setidaknya memuat unsur title, creator, subject, description, date, type, format, identifier, source, language, relation, coverage, dan rights (Pendit, 2009).

Setiap jenis koleksi pada aplikasi Eprints Institutional Repository UIN Sunan Kalijaga memiliki deskripsi koleksi yang berbeda, salah satu contoh adalah thesis. Koleksi yang termasuk dalam kelompok jenis ini adalah tugas akhir seperti skripsi, tesis, dan disertasi. Adapun deksripsinya pada aplikasi Eprints adalah title, abstract, creators, corporate creator, divisions, publication details, journal or publication title, funders, projects, sedangkan koleksi selain thesis, seperti artikel, buku, monograf, video, image, thesis, dan lain sebagainya memiliki informasi deskriptif yang berbeda.

Setelah proses pengidentifikasian informasi deskripsi koleksi, kemudian koleksi beserta deskripsinya (Generate AIP) dikirimkan kepada sistem Institutional Repository UIN Sunan Kalijaga untuk disimpan dan dilestarikan. Petugas atau sivitas akademika akan melakukan "deposite item now" sebagai persetujuan untuk menyerahkan koleksi pada Institutional Repository UIN Sunan Kalijaga (coordinate updates) (Yanto, 2013).

\section{Archival storage (simpanan arsip)}

Cara yang digunakan pengelola untuk mensiasati agar koleksi dapat diterima (receive data) oleh sistem Institutional Repository UIN Sunan Kalijaga adalah memadatkan (compress) ukuran file koleksi. Pemadatan file dilakukan terhadap koleksi yang memiliki ukuran besar agar dapat diakses dengan mudah, menghemat ruang penyimpanan, dan webpage dapat dibuka dengan cepat. File koleksi dengan ukuran kecil disimpan di server online, sedangkan file ukuran besar disimpan di server offline. Sesuai pernyataan informan bahwa "Kalo filenya yang besar tetep tersimpan di server PTIPD kemudian yang kita compress itu baru yang kita upload ke Digilib yang masuk ke digilib" (SH). Dengan adanya pemadatan ukuran file, terkadang membuat kualitas koleksi Institutional Repository UIN Sunan Kalijaga menjadi berkurang, sehingga koleksi asli seperti saat diunggah perlu disimpan.

Pengaturan jejak penyimpanan data (manage storage hierarchy) Institutional Repository UIN Sunan Kalijaga dilakukan oleh Bagian Sistem Informasi dan Jaringan di dua server berbeda, server pertama terletak di PTIPD yang berkapasitas 350 GB (gigabyte) sebagai pangkalan data online untuk diakses pengguna, dan server kedua terletak di lantai dua Perpustakaan UIN Sunan Kalijaga berkapasitas 500 GB sebagai backup dan pangkalan data offline yang diakses petugas. Perpustakaan juga melakukan pemantauan kerusakan (error checking) dan backup (disaster recovery) terhadap data dan folder Eprints Institutional Repository UIN Sunan Kalijaga. Backup dilakukan di empat tempat, yaitu di server PTIPD, server Perpustakaan UIN Sunan Kalijaga, server Digilib, dan harddisk external. Kegiatan tersebut dilakukan tanpa panduan atau terjadwal secara tertulis, namun selalu dilakukan minimal seminggu sekali pada database dan minimal sebulan sekali pada folder atau direktori aplikasi Eprints. Pemantauan kerusakan dan pencadangan tersebut dilakuan guna mengantisipasi apabila Institutional Repository UIN Sunan Kalijaga rusak atau hilang, sehingga database dan folder tersebut dapat dikembalikan seperti semula.

Migrasi hardware dan software juga pernah dilakukan oleh Perpustakaan UIN Sunan Kalijaga terhadap spesifikasi server. Pemutakhiran hardware pernah dilakukan dari memory RAM 4 GB menjadi 8 GB, dan sekarang baru ada pembaruan kapasitas server dari 350 GB menjadi 1 TB (terabyte), dan 500 GB menjadi 2 TB. Pembaruan software juga pernah dilakukan terhadap aplikasi Eprints dari versi 2.0 menjadi versi 3.0 seperti yang sekarang digunakan Institutional Repository 
UIN Sunan Kalijaga. Pemutakhiran hardware dan software tersebut dilakukan pada tahun 2013 dan 2015 untuk meningkatkan daya simpan, akses, dan fitur agar compatible dengan teknologi yang terus berkembang.

Bentuk perawatan, penyimpanan, pemantauan, pencadangan, serta pemutakiran yang dilakukan pengelola Institutional Repository UIN Sunan Kalijaga di atas menunjukkan bahwa Institutional Repository UIN Sunan Kalijaga menyimpan setiap koleksi beserta datanya agar dapat tersedia untuk temu kembali (provide data) di masa mendatang.

\section{Data management (manajemen data)}

Metadata dekripsi pada aplikasi Eprints selalu dimutakhirkan dengan memasukkan setiap data koleksi baru oleh Bagian Preservasi dan Repository Digital (administer database). Metadata deksriptif juga terkadang perlu diubah sesuai permintaan dari penulis atau penyetor koleksi akibat adanya kesalahan atau kekurangan (receive database updates).

Metadata deskripsi pada aplikasi Eprints Institutional Repository UIN Sunan Kalijaga merupakan metadata standar Dublin Core yang sudah dimodifikasi sesuai dengan kebutuhan UIN Sunan Kalijaga. Modifikasi metadata deskripsi tersebut adalah sebagai berikut: (a) Mengadopsi ANZSRC (Australian and New Zealand Standard Research Classification) sebagai subjek area pada aplikasi Eprints yang digunakan Institutional Repository UIN Sunan Kalijaga dalam mengelompokkan karya penelitiannya. (b) Mengembangkan area subjek ke-Islaman untuk penelitian yang membutuhkan area pengelompokan lebih spesifik. (c) Merencanakan daftar kata kunci untuk memudahkan pengelola menetapkan identifikasi bagi koleksi yang membahas suatu ilmu sangat luas dan multidisiplin ilmu.

Selain deskripsi metadata, aplikasi Eprints Institutional Repository UIN Sunan Kalijaga juga dapat menunjukkan data statistik perkembangan pengelolaan repository (generate report), antara lain jumlah pengunjung per tahun, jumlah koleksi yang diunduh, browser yang sering digunakan pengguna untuk mengakses, jumlah jenis koleksi yang disimpan, anggota yang sering mengkases, dan masih banyak data lainnya. Sampai tanggal 28 Juli 2016, Institutional Repository UIN Sunan Kalijaga telah diunduh sebanyak 8.813.150 (delapan juta delapan ratus tigas belas ribu seratus lima puluh) pengguna.

Sistem dan pangkalan data Institutional Repository UIN Sunan Kalijaga selalu dipantau oleh Bagian Sistem Informasi dan Jaringan Perpustakaan UIN Sunan Kalijaga, pemantauan ini dilakukan untuk memastikan bahwa sistem Institutional Repository UIN Sunan Kalijaga dapat bekerja dengan baik dan data Institutional Repository UIN Sunan Kalijaga terjamin dan selalu dapat diakses oleh pengguna.

Data deskriptif dan administratif koleksi dibuat untuk memudahkan tidak hanya kepada pengguna, namun juga kepada petugas. Setiap data koleksi yang telah dikelola petugas disediakan untuk menjawab permintaan pengguna (perform queries) dan diharapkan dapat mewakili setiap koleksi. Oleh karena itu, pengelola Institutional Repository UIN Sunan Kalijaga perlu merencanakan strategi reservasi atau pemesanan agar koleksi yang disimpan dapat dilestarikan.

\section{Preservation planning (perencanaan preservasi)}

Institutional Repository UIN Sunan Kalijaga secara teknis dikelola oleh Bagian Preservasi dan Repository Digital dan Bagian Sistem Informasi dan Jaringan Perpustakaan UIN Sunan Kalijaga. Bagian tersebut lebih mengetahui apa saja kebutuhan dan kegiatan yang seharusnya dilakukan agar perencanaan dapat diusulkan kepada pimpinan perpustakaan. Usulan yang sudah diupayakan untuk pengembangan Institutional Repository UIN Sunan Kalijaga antara lain memperbanyak konten, mengembangkan sumber daya manusia, mengoptimalkan upload mandiri, mengembangkan area subjek, mengadakan alat pendukung seperti server untuk menambah 
kapasitas file digital, NAS (Network-attached storage) yakni server yang dapat diakses langsung melalui jaringan area lokal, dan genset sebagai cadangan sumber tegangan listrik untuk mengantisipasi terjadi pemadaman listrik (develop preservation strategies and standarts).

Perpustakaan UIN Sunan Kalijaga juga melestarikan koleksi Institutional Repository UIN Sunan Kalijaga dengan melakukan emolution (Yanto, 2013), yakni penyimpanan data yang tidak hanya pada sebuah media, tetapi juga menyalin pada media penyimpanan lain (backup) terutama pada harddisk external untuk mengantisipasi adanya ancaman kerusakan atau kehilangan seperti serangan virus atau bencana alam, mengingat Kota Yogyakarta adalah daerah rawan gempa bumi dan gunung meletus. Walaupun kegiatan tersebut tidak terencana (dipandu secara tertulis oleh suatu pedoman), namun usaha tersebut sebenarnya sudah dilakukan Perpustakaan UIN Sunan Kalijaga sebagai bentuk strategi preservasi. Perencanaan preservasi diakui oleh Perpustakaan UIN Sunan Kalijaga masih lemah (Yanto, 2013), karena harus menjamin keberadaan Institutional Repository UIN Sunan Kalijaga di masa mendatang, walaupun strategi preservasi yang dilakukan bersifat sporadis (tidak berdasarkan pada suatu kebijakan yang terencana) dan hanya kebijakan dalam bentuk tertulis yang tidak terukur, namun secara eksplisit, kegiatan-kegiatan yang sudah dilakukan menggambarkan adanya perencanaan preservasi.

Perpustakaan UIN Sunan Kalijaga juga mempunyai strategi lain yang menurutnya penting, yakni menjamin sumber daya manusia (SDM) tetap selalu bekerja, artinya Perpustakaan UIN Sunan Kalijaga akan mengupayakan petugas status kontrak agar diangkat menjadi pegawai tetap, harapannya Institutional Repository UIN Sunan Kalijaga dapat dikelola dan dikembangkan dengan semangat kerja. Pengembangan SDM Institutional Repository UIN Sunan Kalijaga diakui menjadi strategi yang paling efektif atas keberlangsungan institutional repository, sesuai dengan sejarah pendiriannya bahwa pembangunan Institutional Repository UIN Sunan Kalijaga pertama kali yang disiapkan adalah SDM (Yanto, 2013), karena komponen satu-satunya yang hidup dalam suatu organisasi adalah SDM, sehingga tanpa adanya pengelola atau SDM, Institutional Repository UIN Sunan Kalijaga tidak akan terselenggara apalagi dapat dilestarikan.

Strategi lain yang mengarah pada pelestarian Institutional Repository UIN Sunan Kalijaga adalah memperbarui perangkat keras dan perangkat lunak secara terus-menerus seperti upgrade aplikasi Eprints, menambah kapasitas bandwith internet (Yanto, 2013), serta menambah spesifikasi server. Dengan melakukan kegiatan-kegiatan tersebut, secara eksplisit Institutional Repository UIN Sunan Kalijaga menunjukkan adanya pemantauan perkembangan teknologi (monitor technology), agar institutional repository yang diselenggarakan dapat competibel dengan teknologi terbarukan, dapat menyimpan secara terus menerus, dan selalu dapat diakses di masa mendatang.

\section{Access (akses)}

Sebagai layanan terhadap pengguna untuk mendapatkan informasi, Institutional Repository UIN Sunan Kalijaga telah menyediakan antarmuka website (www.digilib.uin-suka.ac.id). Website tersebut menyediakan berbagai menu layanan sebagai sarana permintaan terhadap koleksi (coordinat access activities). Menu yang disediaakan antara lain adalah variasi penelusuran yang terdiri atas pencarian (search) dan penjelajahan (browse). Pencarian dapat dilakukan secara sederhana atau spesifik, sedangkan penjelajahan dapat dilakukan berdasarkan divisi, tahun, subjek, jenis koleksi, dan unggahan terbaru. Hal tersebut dilakukan Perpustakaan UIN Sunan Kalijaga agar pengguna dapat memilih varian penelususran dan cepat menemukan koleksi yang dicari, serta harapannya juga dapat memberikan informasi lain yang masih berkaitan dengan koleksi yang diinginkan.

Perpustakaan UIN Sunan Kalijaga memiliki kebijakan tersendiri dalam menyediakan koleksi khusus tugas akhir, yakni pengguna yang mengakses koleksi tugas akhir (skripsi, tesis, 
dan disertasi) hanya dapat mengunduh file koleksi bagian awal, bab satu, bab akhir dan daftar pustaka saja atau lampiran. Apabila pengguna menginginkan koleksi tersebut secara fulltext, maka pengguna harus menjadi sivitas akademika UIN Sunan Kalijaga dan mengikuti syarat lain yang tertuang dalam 'Kebijakan pengelolaan dan akses koleksi digital Perpustakaan UIN Sunan Kalijaga 2012' (Arianto, 2012), tetapi untuk koleksi selain tugas akhir, pengguna dapat mengkases secara fulltext termasuk mengunduhnya. Penguna juga dapat meminta kepada pengelola Institutional Repository UIN Sunan Kalijaga melalui berbagai media seperti surat dan media sosial Facebook, permintaan tersebut kebanyakan adalah pengguna yang ingin mengkases koleksi tugas akhir secara fulltext. Pembatasan dan adanya permintaan yang telah ditanggapi Perpustakaan UIN Sunan Kalijaga menunjukkan bahwa informasi dikemas sedemikian rupa untuk diberikan kepada pengguna agar sesuai keperuntukannya (generate DIP). Perpustakaan UIN Sunan Kalijaga ingin menjaga legalitas karya Institutional Repository UIN Sunan Kalijaga yang dimilikinya agar dapat menjadi kontrol bagi karya-karya lain yang serupa (Yanto, 2013).

Perpustakaan UIN Sunan Kalijaga telah menjadi koordinator layanan, mulai dari pembatasan, permintaan, dan tanggapan untuk menjawab semua permintaan pengguna (deliver response). Semua kegiatan tersebut dilakukan melalui koordinasi dengan komponen lain yang secara menyeluruh dilaksanakan oleh bagian-bagian penting Institutional Repository UIN Sunan Kalijaga yakni komponen administrasi.

\section{Administration}

Pengelolaan Institutional Repository UIN Sunan Kalijaga dilakukan oleh Bagian Preservasi dan Repository Digital dan Bagian Sistem Informasi dan Jaringan di bawah Perpustakaan UIN Sunan Kalijaga. Bagian Preservasi dan Repository Digital berfungsi melayani perjanjian penyerahan koleksi yang disediakan oleh perpustakaan, namun perjanjian tersebut masih bersifat baku, belum menawarkan pilihan negosiasi secara rinci terhadap koleksi yang diserahkan oleh producen (negotiate submission agreement). Bagian tersebut juga melayani pembaruan koleksi (archival information update) ketika ada permintaan dari pemilik koleksi akibat kekurangan atau adanya kerusakan. Bagian tersebut juga bertugas menentukan bagian koleksi mana yang dapat didayagunakan dan pengguna mana yang berhak menjadi anggota (physical access control) sesuai aturan yang tertuang dalam 'Kebijakan pengelolaan dan akses koleksi digital Perpustakaan UIN Sunan Kalijaga 2012' (Arianto, 2012). Perpustakaan UIN Sunan Kalijaga sebenarnya juga sudah memiliki rencana untuk membuka keseluruhan bagian koleksi tugas akhir tersebut agar dapat diakses oleh siapa saja, namun Rektor UIN Sunan Kalijaga memiliki kebijakan agar koleksi tetap terbatas bagi pengguna khususnya dari luar UIN Sunan Kalijaga, hal ini dilakukan atas dasar hasil roadshow ke fakultas di UIN Sunan Kalijaga bahwa 50\% menyetujui dan 50\% tidak menyetujui koleksi tugas akhir untuk dibuka secara menyeluruh ( $\mathrm{SH})$.

Tugas lain dari Bagian Preservasi dan Repository Digital Perpustakaan UIN Sunan Kalijaga adalah melakukan verifikasi serta menentukan layak atau tidaknya koleksi yang diserahkan dan didistribusikan (khususnya karya tugas akhir mahasiswa), koleksi dapat ditolak apabila tidak sesuai dengan 'Prosedur Tetap Bebas Pustaka dan Unggah Tugas Akhir Mandiri Perpustakaan UIN Sunan Kalijaga Yogyakarta' (Arianto, 2012). Bagian tersebut juga bertugas melayani keanggotaan melalui aplikasi Eprints dengan tiga level/tingkatan. Tingkat paling bawah adalah anggota biasa yang hanya dapat mengajukan atau mengirimkan koleksi, tingkat menengah yakni staf yang tidak hanya dapat mengajukan koleksi, tetapi juga mengulas serta menyetujui layak tidaknya suatu koleksi untuk diarsip, dan tingkat paling atas adalah administrator yang dapat melakukan kegiatan level bawah dan menengah, bahkan sampai dapat mengatur sistem Eprints seperti membuat, mengubah, dan menghapus akun anggota (customer service). Sedangkan pada Bagian Sistem Informasi dan Jaringan Perpustakaan UIN Sunan Kalijaga selalu melakukan tugasnya antara lain 
memantau, memelihara, mengaudit, dan melaporkan distribusi kinerja sistem (manage system configuration) walaupun tidak terjadwal, acak, dan tidak terdokumentasi.

Dua bagian tersebut di atas saling bekerjasama mengelola Institutional Repository UIN Sunan Kalijaga dengan tugasnya masing-masing setiap hari. Pada Bagian Sistem Informasi dan Jaringan mengurusi aplikasi Eprints, database, server, dan jaringan, sedangkan Bagian Preservasi dan Repository Digital mengelola konten Institutional Repository UIN Sunan Kalijaga. Kedua bagian tersebut merupakan bagian paling penting untuk menentukan kebijakan dan standar institutional repository (establish standards and policies) karena lebih memahami akan kebutuhan Institutional Repository UIN Sunan Kalijaga.

Enam entitas di lingkungana internal di atas merupakan bagian Institutional Repository UIN Sunan Kalijaga yang memiliki fungsi masing-masing dengan tujuan melestarikan dan selalu menyediakan akses ke koleksi digital. Keenam bagian tersebut di atas secara sepintas mengelola objek digital yang mengandung kemasan informasi yang harus dilestarikan, objek tersebut juga terasa pada bagian luar sistem yakni dari producer kepada sistem, dan dari sistem kepada cunsomer.

\section{Kemasan Informasi dan Objek Institutional Repository UIN Sunan Kalijaga}

Informasi digital merupakan suatu objek yang menjadi konsentrasi dalam kegiatan pelestarian model OAIS, objek tersebut diproses dari producer ke dalam sistem OAIS, kemudian di dalam sistem OAIS, objek diproses antar entitas sistem OAIS, dan pada akhirnya dari sistem diproses menuju consumer. Proses tersebut nampak sebagai suatu kemasan informasi yang mengandung koleksi yang harus dilestarikan bersamaan dengan metadata yang telah diikat, sehingga kemasan informasi di dalam pengelolaan Institutional Repository UIN Sunan Kalijaga objek tersebut dapat dibagi menjadi 3 (tiga). yaitu Submission Information Package (SIP), Archival Information Package (AIP), dan Dissemination Information Package (DIP).

\section{Submission Information Package (SIP)}

Koleksi yang dapat diterima Institutional Repository UIN Sunan Kalijaga untuk disimpan dalam aplikasi Eprints adalah koleksi yang berbentuk softcopy, baik itu dari alih media bentuk hardcopy atau koleksi asli dalam bentuk softcopy. Producen terkadang menyerahkan koleksi dalam bentuk hardcopy ke pertugas untuk dialihmediakan menjadi bentuk softcopy agar koleksi dapat diterima aplikasi Eprint yang digunakan. Media yang digunakan dalam penyerahan koleksi softcopy dari producer adalah flash memory, CD, atau melalui aplikasi dalam http://pustaka.uin-suka.ac.id. Format koleksi digital yang diterima aplikasi Eprints dapat bentuk apa saja, baik itu kelompok teks, gambar, suara, video, maupun aplikasi seperti android. Aplikasi Eprints menyediakan empat kolom untuk kelompok bentuk koleksi, yakni: file, zip, tar.gz, dan url. Deskripsi informasi yang terkandung di dalam koleksi juga turut disertakan oleh producer ketika menyerahkan softcopy koleksi. Deskripsi koleksi informasi dapat dicantumkan di dalam metadata Eprints yang telah tersedia seperti title, abstract, creators, corporate creator, divisions, publication details, journal or publication title, funders, projects. Setiap bentuk koleksi memiliki deksipsi informasi koleksi yang berbeda-beda, deskripsi informasi koleksi tersebut beserta bentuk softcopy koleksi merupakan sebuah kemasan informasi dan objek yang siap dicerna oleh lingkungan internal dalam Institutional Repository UIN Sunan Kalijaga.

\section{Archival Information Package (AIP)}

Tiap-tiap koleksi yang telah dimasukkan di dalam Eprints dibuatkan deskripsi metadata dan administrasi layaknya koleksi asli supaya dapat diakses oleh pengguna maupun mesin pencari. Deskripsi informasi tersebut berisi sebuah kemasan informasi yang mengandung content 
information dan preservation description information.

\section{Content Information}

Merupakan keterangan yang menggambarkan isi koleksi, keterangan tersebut berupa Content Data Object dan Representation Information. Content Data Object adalah visualisasi isi koleksi yang dapat dilestarikan. Institutional Repository UIN Sunan Kalijaga menyimpan koleksi yang terdiri atas teks, gambar, suara, video, dan aplikasi seperti android yang dapat ditemukan di setiap informasi metadata koleksi pada aplikasi Eprints, seperti dalam pencarian spesifik, format koleksi menjadi pilihan bagi pengguna yang ingin mencari bentuk koleksi. Adapun format koleksi yang selama ini disimpan antara lain PDF, Word, Excel, Power Point, JPG, PNG, MP3, MPG, MP4, AVI, VOB, APK dan format lainnya. Representation information merupakan keterangan isi koleksi yang dapat dipahami oleh pengguna. Aplikasi Eprints Institutional Repository UIN Sunan Kalijaga dapat menampilkan abstrak, jenis koleksi, dan ukuran file yang dapat menjadi preview pengguna sebagai gambaran isi koleksi sebelum melakukan tindak lanjut untuk memperoleh koleksi, seperti jenis koleksi, format koleksi, ukuran file, abstrak, bahkan pratinjau isi koleksi.

\section{Preservation Description Information}

Preservation Description Information adalah keterangan tambahan yang mendukung koleksi agar dapat disimpan dan dapat ditemukan kembali di masa mendatang. Unsur ini mengandung lima komponen, yakni reference, context, provenance, fixity, dan access rights. Reference merupakan nomor unik yang diberikan oleh sistem atau di luar sistem untuk mengidentifikasi koleksi. Aplikasi Eprints secara otomatis memberikan nomor ID untuk setiap koleksi yang baru dimasukkan pada Institutional Repository UIN Sunan Kalijaga. Koleksi khususnya buku dan jurnal juga terkadang memiliki ISBN atau ISSN yang dapat disertakan pada data entry apalikasi Eprints sebagai identitas koleksi. Context adalah keterangan yang dapat berkaitan dengan konten lain di luarnya. Saat koleksi dimasukkan pada Institutional Repository UIN Sunan Kalijaga, petugas menentukan subjek dan divisi koleksi sesuai dengan subjek area dan divisi yang sudah dikembangkan pada aplikasi Eprints Institutional Repository UIN Sunan Kalijaga. Hal ini menjadi informasi bahwa masih ada koleksi lain yang berkaitan dengan koleksi tersebut. Provenance adalah dokumentasi histroy koleksi. Eprints Institutional Repository UIN Sunan Kalijaga dapat mencatat history koleksi yang telah masuk. Koleksi yang mulai diunggah akan dicatat tanggal penciptaannya dan apabila ada perubahan, dicatat pula waktu perubahannya.

Fixity merupakan keterangan yang menunjukkan orisinaliats dan integritas koleksi. Koleksi Institutional Repository UIN Sunan Kalijaga khususnya karya ilmiah sudah mengharuskan bagian di dalam isi koleksi memuat hasil scan tandatangan, cap basah, dan materai (lihat 'Prosedur Tetap Bebas Pustaka dan Unggah Tugas Akhir Mandiri Perpustakaan UIN Sunan Kalijaga Yogyakarta' (Hariyanto, 2016a). Hal ini menunjukkan bahwa koleksi yang diserahkan adalah orisinil dan dapat dipertanggungjawabkan. Access Rights merupakan hak untuk mengakses isi koleksi. Petugas telah mengunggah file koleksi Institutional Repository UIN Sunan Kalijaga di aplikasi Eprints. File tersebut dapat diatur siapa saja pengguna yang dapat mengakses koleksi tersebut.

Metadata dalam Institutional Repository UIN Sunan Kalijaga merupakan metadata Dublin Core yang sudah berstandar internasional sehingga mudah dilakukan proses interoperability dengan sistem lain (Yanto, 2013). Metadata dan isi koleksi Institutional Repository UIN Sunan Kalijaga diikat menjadi sebuah kemasan informasi yang diarsip dan dilestarikan agar selalu tersedia kapan saja dibutuhkan oleh pengguna. 
Tabel 1

Rangkuman Hasil Analisis Data Pengelolaan Institutional Repository UIN Sunan Kalijaga berdasarkan model OAIS

\begin{tabular}{|c|c|c|c|c|}
\hline Lingkup & Entitas & Variabel Komponen & Ada & Tidak \\
\hline \multirow[t]{8}{*}{ External } & Producer & Pihak penyelenggara koleksi & $\sqrt{ }$ & \\
\hline & & Memiliki penjanjian/kesepakatan penyerahan & $\sqrt{ }$ & \\
\hline & & Variasi koleksi yang disepakati & & $\sqrt{ }$ \\
\hline & Management & Pihak pemangku kebijakan & $\sqrt{ }$ & \\
\hline & & Upaya pendanaan & $\sqrt{ }$ & \\
\hline & & Evaluasi & $\sqrt{ }$ & \\
\hline & Consumer & Pengguna koleksi & $\sqrt{ }$ & \\
\hline & & Keanggotaan & $\sqrt{ }$ & \\
\hline \multirow[t]{30}{*}{ Internal } & Ingest & Proses penerimaan & $\sqrt{ }$ & \\
\hline & & Penjaminan kualitas & $\sqrt{ }$ & \\
\hline & & Pengolahan AIP (kemasan informasi pengarsipan) & $\sqrt{ }$ & \\
\hline & & Pengolahan deskripsi informasi & $\sqrt{ }$ & \\
\hline & & Penyelarasan pembaruan & $\sqrt{ }$ & \\
\hline & Archival Storage & Penerima data & $\sqrt{ }$ & \\
\hline & & Pengaturan jejak penyimpanan & $\sqrt{ }$ & \\
\hline & & Media pengganti & $\sqrt{ }$ & \\
\hline & & Pemeriksaan kerusakan & $\sqrt{ }$ & \\
\hline & & Pemulihan kerusakan & $\sqrt{ }$ & \\
\hline & & Penyediaan data & $\sqrt{ }$ & \\
\hline & Data Management & Pengelola database & $\sqrt{ }$ & \\
\hline & & Penyajian data atas permintaan & $\sqrt{ }$ & \\
\hline & & Proses pelaporan & $\sqrt{ }$ & \\
\hline & & Penerima pembaruan database & $\sqrt{ }$ & \\
\hline & Preservation Planning & Pemantauan keanggotaan & & $\sqrt{ }$ \\
\hline & & Pemantauan perkembangan teknologi & $\sqrt{ }$ & \\
\hline & & Pengembangan strategi dan standar pelestarian & $\sqrt{ }$ & \\
\hline & & $\begin{array}{l}\text { Pengembangan kemasan desain dan rencana } \\
\text { perpindahan }\end{array}$ & & $\sqrt{ }$ \\
\hline & Access & Penyediaan antarmuka akses & $\sqrt{ }$ & \\
\hline & & Pengolahan DIP (kemasan informasi penyebaran) & $\sqrt{ }$ & \\
\hline & & Menjawab permintaan & $\sqrt{ }$ & \\
\hline & Administration & Negosiasi kesepakatan perjanjian penerimaan & & $\sqrt{ }$ \\
\hline & & Pengaturan sistem konfigurasi & $\sqrt{ }$ & \\
\hline & & Pembaruan informasi arsip & $\sqrt{ }$ & \\
\hline & & Pengaturan akses koleksi & $\sqrt{ }$ & \\
\hline & & Menciptakan standar dan kebijakan & $\sqrt{ }$ & \\
\hline & & Pemeriksaan pengajuan & $\sqrt{ }$ & \\
\hline & & Tanggapan atas permintaan & $\sqrt{ }$ & \\
\hline & & Pelayanan konsumen & $\sqrt{ }$ & \\
\hline \multirow{12}{*}{$\begin{array}{l}\text { Kemasan } \\
\text { Informas } \\
\text { i dan } \\
\text { Objek }\end{array}$} & Submission Information & Softcopy koleksi & $\sqrt{ }$ & \\
\hline & Package (SIP) & Deskripsi koleksi yang diajukan & $\sqrt{ }$ & \\
\hline & Archival Information & Data konten koleksi & $\sqrt{ }$ & \\
\hline & Package (AIP) & Pratinjau & $\sqrt{ }$ & \\
\hline & & Nomor Unik & $\sqrt{ }$ & \\
\hline & & Koleksi yang berkaitan & $\sqrt{ }$ & \\
\hline & & Jejak History & $\sqrt{ }$ & \\
\hline & & Orisinalitas & $\sqrt{ }$ & \\
\hline & & Pengelolaan akses & $\sqrt{ }$ & \\
\hline & Dissemination & Rekayasa koleksi asli & $\sqrt{ }$ & \\
\hline & Information Package & Deskripsi koleksi yang disediakan & $\sqrt{ }$ & \\
\hline & (DIP) & Kebijakan akses koleksi & $\sqrt{ }$ & \\
\hline
\end{tabular}

\section{Dissemination Information Package (DIP)}

Perpustakaan UIN Sunan Kalijaga menyebarkan koleksi Institutional Repository UIN Sunan Kalijaga melalui laman http://digilib.uin-suka.ac.id. Perpustakaan UIN Sunan Kalijaga menyediakan 
deskripsi koleksi agar pengguna dapat mengunduh atau mesin pencari dapat mengindeks. Koleksi yang disebarkan juga terkadang adalah koleksi tidak asli, atau rekayasa, yaitu koleksi hasil olahan dari file berukuran besar yang dipadatkan menjadi ukuran kecil, sehingga menghemat ruang server dan mudah diakses oleh pengguna. Koleksi Institutional Repository UIN Sunan Kalijaga juga tidak seluruhnya dapat diakses oleh pengguna, namun ada koleksi yang dikemas khusus untuk anggota Institutional Repository, yakni koleksi tugas akhir pada bagian Bab II sampai dengan Bab IV atau Bab sebelum terakhir.

Berdasarkan pemaparan di atas, komponen model OAIS yang sudah terpenuhi oleh tata kelola Institutional Repository UIN Sunan Kalijaga dapat dilihat pada Tabel 1. Berdasarkan tabel 1, dapat dilihat bahwa variabel komponen OAIS sebagian besar sudah terpenuhi oleh tata kelola Institutional Repository UIN Sunan Kalijaga dan hanya empat variabel yang belum terselenggara, yakni pada entitas producer (variasi koleksi yang disepakati), entitas preservation planning (monitor designated community, develop packaging designs and migration plans), dan entitas administration (negotiate submission agreement).

\section{SIMPULAN}

Pengelolaan Institutional Repository UIN Sunan Kalijaga Yogyakarta memenuhi komponen model OAIS, mulai dari lingkungan eksternal (producer, management, dan consumer), lingkungan internal (archival storage, data management, preservation planning, access, administration), dan kemasan informasi dan objek yaitu Submission Information Package (SIP), Archival Information Package (AIP), dan Dissemination Information Package (DIP). Namun ada beberapa variabel di dalam komponen yang belum terselenggara, yakni pada lingkungan external dan lingkungan internal.

Kekurangan pada lingkungan external Institutional Repository UIN Sunan Kalijaga terdapat pada entitas producer yakni variasi koleksi yang disepakati, artinya kesepakatan perjanjian penyerahan hanya disediakan untuk koleksi tugas akhir mahasiswa saja, belum untuk koleksi lain. Sementara kekurangan pada lingkungan internal terdapat pada entitas preservation planning (perencanaan pelestarian) yakni monitor designated community atau pemantauan keanggotaan, develop packaging designs and migration plans atau pengembangan strategi pelestarian dan standar, dan pada komponen administration yakni negotiate submission agreement atau negosiasi kesepakatan/perjanjian penyerahan koleksi.

Model OAIS memiliki komponen dan entitas yang sangat spesifik dengan variabelnya, sehingga model ini merupakan model yang sangat direkomendasikan untuk diadopsi oleh Institutional Repository UIN Sunan Kalijaga. Dengan melengkapi kekurangan variabel di atas, model OAIS sudah menjadi standar yang stabil bagi Perpustakaan UIN Sunan Kalijaga dalam mengelola Institutional Repository UIN Sunan Kalijaga.

\section{DAFTAR PUSTAKA}

Arianto, M. S. (2012). Kebijakan Pengelolaan dan Akses Koleksi Digital Perpustakaan UIN Sunan Kalijaga 2012. Perpustakaan UIN Sunan Kalijaga.

Arianto, M. S., \& Subhan, M. (2012). Isu-isu Pengembangan Perpustakaan Digital di Indonesia. http://digilib.uinsuka.ac.id/7051/1/IsuPengembangan_PerpusDigital_2012.pdf

Bradley, K., Lei, J., \& Chris Blackall. (2007). Towards an Open Source Repository and Preservation System. In UNESCO. https://www.semanticscholar.org/paper/Towards-anOpen-Source-Repository-and-Preservation-BradleyLei/f66d32e2d5746973f3ee0eab46057ecd4549425e 
Consejo Superior de Investigaciones Científicas (CSIC). (2004). Welcome to Ranking Web of Repositories | Ranking Web of Repositories. http://repositories.webometrics.info/en

Consultative Committee for Space Data Systems (CCSDS). (2012). Reference Model for an Open Archival Information System (OAIS): Recommended Practice CCSDS 650.0-M-2. In Megenta Book. https://doi.org/10.1081/E-ELIS3-120044377

Hariyanto, S. (2016a). Prosedur Tetap Bebas Pustaka dan Unggah Tugas Akhir Mandiri Perpustakaan UIN Sunan Kalijaga Yogyakarta. Perpustakaan UIN Sunan kalijaga.

Hariyanto, S. (2016b). Prosedur Upload File Karya Ilmiyah civitas akademika ke digilib. Perpustakaan UIN Sunan Kalijaga. http://digilib.uin-suka.ac.id/19739/1/Prosedur Upload File Karya Ilmiyah civitas akademika ke digilib.pdf

Hitchcock, S., Brody, T., Hey, J. M. N., \& Carr, L. (2007). Digital preservation service provider models for institutional repositories: Towards distributed services. D-Lib Magazine, 13(5-6). https://doi.org/10.1045/may2007-hitchcock

Jones, R., Andrew, T., \& MacColl, J. (2006). The Institutional Repository. In The Institutional Repository. https://doi.org/10.1533/9781780630830

Pendit, P. L. (2009). Perpustakaan Digital: Kesinambungan dan Dinamika. Cita Karya Karsa Mandiri.

Pendit, P. L. (2015). Apa Yang (Sesungguhnya) Dimaksud Perpustakaan Digital (digital libraries). $\quad$ https://www.facebook.com/notes/putu-laxman-pendit/apa-yangsesungguhnya-dimaksud-perpustakaan-digital-digitallibraries/10154365721110968?_rdc=1\&_rdr

Priyanto, S. (2012). Evaluasi Pengelolaan UNDIP Institutional Repository [Universitas Islam Negeri Sunan Kalijaga]. http://eprints.undip.ac.id/37075/

Reitz, J. M. (2004). ODLIS: Online Dictionary for Library and Information Science. https://products.abc-clio.com/ODLIS/odlis_about.aspx

Universitas Islam Negeri Sunan Kalijaga. (2015). Deposits - Institutional Repository UIN Sunan Kalijaga. http://digilib.uinsuka.ac.id/cgi/stats/report/deposits?range=ALL\&from=\&to=

Yanto. (2013). Pengelolaan Institutional Repository Perpustakaan Perguruan Tinggi (Studi Kasus di Perpustakaan UIN Sunan Kalijaga Yogyakarta) [Universitas Islam Negeri Sunan Kalijaga]. http://digilib.uin-suka.ac.id/12296/

Yeates, R. (2003). Institutional repositories. VINE, 33(2), 96-101. https://doi.org/10.1108/03055720310509064 